\title{
Analysis on influencing factors of higher education resource structure optimization
}

\author{
Li Zhang, Hongying Gao
}

Harbin University of Commerce, Harbin, Heilongjiang Province, China

Keywords: Higher education; Resource structure; optimization

\begin{abstract}
Higher education resource structure optimization is a dynamic process involving multiple factors such as target, environment, power and operation mechanism. These factors interact with each other to influence the optimization degree, direction and final effect of higher education resource structure. The influence factors of the higher education resource structure optimization including the influence of social environment, the change of social class, economic development, political factors, the influence of institutions of higher learning discipline (speciality) replication mode and the influence of institutions of higher learning resources flow barriers. The core of establishing an appropriate and effective management mechanism for higher education lies in the structural optimization of various education resources.
\end{abstract}

\section{Introduction}

The resources of higher education usually refer to the resources that constitute, maintain, participate and serve the higher education system, which is the sum of various production factors needed for the development of higher education and the basic guarantee and condition for the exploitation and development of higher education. Higher education resource structure refers to the combination and connection forms of various resource elements. The change of the higher education resource structure determines its overall functional level to a large extent. It stipulates the performance of all its internal elements, so that all its internal elements have performance that is impossible when they exist alone. The optimization of the structure of higher education resources has an important influence and restrictive effect on the overall function of the system.

\section{The influence of the social environment}

\subsection{Changes in social class.}

In the 30 years of reform and opening up, China's social class structure has undergone fundamental changes. During the planned economy period, the political, institutional, or administrative standards (such as political identity, residence status, and administrative file status) that determine people's socioeconomic status are gradually replaced by new factors, The division of occupation, the widening of income gap and the emergence of private forms of assets have made the division of social strata clearer. The literature puts forward the theoretical framework for dividing social strata based on occupational classification and taking the occupancy of organizational resources, economic resources and cultural resources as the standard. In contemporary Chinese society, the occupancy of economic resources, organizational resources and cultural resources determines people's comprehensive socio-economic status, determines the social evaluation of others to an individual, and also determines the individual's social evaluation for their own. The distribution difference of the three kinds of resources in the population is the surface phenomenon of socio-economic differentiation. However, the most concern of class theorists is not the surface phenomenon of the allocation of resources, but the cause of the difference in resource allocation and the possible social and political consequences of this difference. According to this, ten social strata are divided. 


\subsection{Economic development.}

Firstly, the imbalance of regional economic development has led to regional imbalance in the development of higher education. According to the level of economic development, Mr. Wang Shanmai, a famous education economist, divided the more than 30 provinces (cities) into four categories: The first category is the most developed areas in Beijing, Tianjin and Shanghai; The second category is developed regions such as Liao, Su, Zhejiang, Shandong and Guangdong; The three types of areas are the underdeveloped areas such as Hebei, Jin, Ji, Hei, Wan, Min, Yu, Xiang, Hubei, Sichuan and Xinjiang; The four category is the least developed areas such as the remaining provinces. Due to the differences in the level of economic development among different regions, the gap between the per capita education expenditure and the allocation of educational resources is quite significant. According to statistics, per capita education funds in the first-class areas are always 2-3 times higher than those in the third- and fourth-category areas, and per capita education funds in the second-class areas are higher than $44 \%$ in the three types of areas. The allocation of educational resources directly results in the gap between the quality, level, quantity and speed of higher education in different regions of China.

Secondly, the principle of market economy pursuing efficiency priority also strengthens the irrational structure of higher education resources in the short term. We are currently choosing a planned socialist market economic system. The main goal of the market economy is efficiency. Therefore, the report of the 15th National Congress of the Communist Party of China clarified that the general principle of our country at this stage is "giving priority to efficiency and giving consideration to fairness". In education, in order to pursue the efficiency of education, we have also industrialized and marketized the public welfare education. Even trying to boost domestic consumption and promote economic development through stimulating consumption of education. Especially in the field of higher education, we study the practices of market economy countries, adopt such measures as production and study cooperation, school enterprise contact, unity of teaching and scientific research, creation of Science Park, privatization of higher education, industrialization of higher education, socialization of higher education and the socialization of logistics in Higher Education, aiming at improving the efficiency of higher education. At present, the education market in China has begun to take shape. However, there is a significant gap between the market equity of education and the social equity of education, which makes education neglecting social equity when pursuing efficiency. This is because the social equity of education is based on equality and the goal is to achieve equal opportunities for education. From the perspective of market, the market equity of education is based on inequality, and the goal is to achieve educational efficiency, which is bound to make a difference in the distribution of educational opportunities. When education goes to the market and education can be traded as a commodity, there will be a situation in which who spends money and who is educated. The social equity of education becomes an ideal.

\subsection{Political factors.}

Just as economic factors influence the development of higher education, political factors play a greater role. The political tendency of the country's laws and policies has a major impact on its resource construction. For example, support for a certain region and the strengthening or weakening of a certain industry directly affect the development direction of higher education.

The decentralization of higher education management power has strengthened the irrationality of higher education resources structure to a certain extent. For developed regions, their economy is sufficient to support the survival and development of local higher education. Compared with before, even to a large extent, it has revitalized higher education, so that the operation of higher education and the economic development show a virtuous circle, which promote and complement each other. The economically backward old industrial areas and the old, the young, the marginal, and the poor are not optimistic or even worrying. Taking the old industrial base as an example, the economic transformation is difficult because the economic transformation of the old industrial base requires sufficient financial support. Local governments are already struggling to cope with the economic 
downturn, and they are even less concerned about education, The quality and quantity of higher education has become a problem. Further, the degree of development of higher education is directly determined by the size, structure and quality of resources, which also explains the decisive role of social and political factors in the structural changes of higher education resources.

\section{The influence of the discipline (speciality) replication model in higher education institutions}

At the end of the last century, there were some strange phenomena in China's higher education: Regardless of their own characteristics, basically pursue a large and comprehensive model, trying to build First-class international comprehensive college. Under this ideology, Zhejiang University began the era of the merger of higher education institutions. However, the successful merger case is not much compared to the expected ideal goal. By the beginning of this century, there are still some institutions of higher learning that do the same thing under the constraints of certain forces. This mode of replication has hindered the development of higher education to some extent.

The establishment and development of higher education institutions is the same as that of key higher education institutions and the higher education model that has adopted the new model. It is precisely because of this same-direction and blind competition that the internal consumption between higher education institutions is increasing, which Seriously affecting the healthy and normal development of the higher education industry, hindering the "resonance" effect produced by various higher education institutions and various disciplines, hindering the improvement of the overall level of higher education.

In the construction of disciplines (specialities), if certain disciplines (specialities) newly established in some institutions of higher learning suddenly succeed, then the discipline (speciality) is quickly imitated within a certain range. Such as computer craze, bioengineering craze,, economic management craze,, logistics craze, financial engineering craze, etc. The institutions of higher learning that established these disciplines (professionals) did not consider their own nature, resource constraints, and characteristics. They simply imitated them, which made certain disciplines heat up quickly. However, due to the characteristics of higher education, they quickly cooled down. The reason is very simple, The profession which is not suitable for its own characteristics will not become its core competitiveness eventually. Due to the existence of this replication model, there is a certain internal friction in higher education resources.

\section{The Influence of Barriers to resource flow in higher education institutions}

At present, the main problem in the allocation of educational resources by the education administration is that the allocation of resources is not effectively regulated at the macro-level, but based on the demand for resources by each micro-subject. Once the educational resources are allocated, the resources are settled in one house and "still" in one house. The educational administration seldom considers how to make resources serve more people in a certain time and space. For example, the purchase of large-scale teaching and research valuable equipment is often comprehensively considered from the common needs and development of a school rather than several schools. Although the government strongly advocates resource sharing, there are also provisions in the Higher Education Law. However, most of the institutions that have been formed by the institutions of higher learning for many years have a view on the occupy and use of resources, and there are no specific measures to ensure that resource sharing is difficult to achieve.

It can be seen that we should establish a suitable and effective higher education management mechanism. One of the most appropriate ways is to regard similar institutions of higher learning as the same region and adopt the same management mode for the same region. That is to guide the macro-control from the perspective of the higher education region, and at the micro level, it is recommended that all institutions of higher learning establish reasonable exchanges and strengthen the flow of resources within the same region, especially knowledge resources. The core of this strategy lies in the structural optimization of various educational resources. From this perspective, the significance of the optimization of the resource structure of higher education is even more 
important.

\section{References}

[1] Zhang Liucheng. Application Prospect of Block Chain Technology in Accounting Industry,2018 International Conference on Mechatronics Engineering and Computer Sciences(ICMECS 2018). IEEE, 2018:559-562.

[2] Zhang Liucheng, Chen Meizhi. The analysis of the deep processing industry of agricultural products and strategy in Heilongjiang Province,2018 International Conference on Mechatronics Engineering and Computer Sciences(ICMECS 2018). IEEE, 2018:568-572.

[3] Zhang Liucheng. Impact of Block-Chain Technology on Auditing, 2018 International Conference on Mechatronics Engineering and Computer Sciences (ICMECS 2018). IEEE, 2018:573-577.

[4] Zhang Liucheng. Data Reliability Research on Accounting Information System Based on Block Chain Technology, 2018 International Conference on Mechatronics Engineering and Computer Sciences (ICMECS 2018). IEEE, 2018:604-607.

[5] Zhang Liucheng. Application and Analysis of Witkey Mode In Network Economy [J]. Advances in Social Science, Education and Humanities Research, 2015(31), pp. 178-181

[6] Zhang Liucheng. The Research and Innovation of Witkey Mode under the New Era [J]. Advances in Education Research, 2015 (11) , pp. 102-105.

[7] Zhang Liucheng. Research on the problems of the application of XBRL financial statement in small and medium sized enterprises [J]. Advances in Social Science, Education and Humanities Research, 2016 (59), pp. 1421-1424 